\title{
¿Cómo generar capital social en contextos de exclusión?: Experiencias de organizaciones comunitarias y sus redes sociales*
}

\author{
Pablo Forni** y Mariana Nardone***
}

\begin{abstract}
Resumen
El crecimiento de la pobreza durante las dos últimas décadas en la Argentina ha tenido su correlato en el surgimiento y desarrollo de gran cantidad de organizaciones comunitarias entre los excluidos. Su articulación en una variedad de redes inter-organizacionales incluyendo maquinarias políticas clientelísticas, movimientos piqueteros, redes de base, programas sociales, ONGDs, fundaciones donantes, etc. es fundamental para comprender sus trayectorias. Con anterioridad hemos analizado diferentes tipos de articulación en red en barrios del Gran Buenos Aires. Actualmente nos concentramos en casos que demuestran ser exitosos en la generación de formas de capital social en contextos de exclusión.
\end{abstract}

Palabras clave: capital social, redes sociales, organizaciones de la sociedad civil, pobreza, exclusión

\begin{abstract}
The growth of poverty during the two last decades in Argentina has had its correlate in the sprouting and development of a great amount of communitarian organizations in the excluded. Its expansion into a variety of inter-organizational networks including client wise political mechanisms, picket movements, base networks, social programs, ONGDs, donors' institutions, amongst others, is fundamental to understand its pathways. We have previously analyzed different types of cooperative tasks in network in Buenos Aires districts. At the moment, we concentrated ourselves on cases that demonstrate to be successful in the generation of forms of social capital in exclusion contexts.
\end{abstract}

Key words: social capital, social networks, nonprofit sector (i?), poverty, exclusion

Ponencia presentada al "X Colóquio Internacional sobre Poder Local" (11-12-13 de dezembro de 2006 .

* Licenciado en Sociología, Universidad del Salvador. M.A. y Ph.D. en Sociología, University of Notre Dame.Email: forni@mail.retina.ar.

** Licenciada en Sociología. Investigadora Adjunta en el Área de "ONGs y Políticas Públicas" del Instituto de Investigación en Ciencias Sociales (IDICSO) de la Universidad del Salvador. 
¿Cómo generar capital social en contextos de exclusión?:Experiencias de organizaciones comunitarias y sus redes sociales - Pablo Forni y Mariana Nardone

\section{Introducción}

El análisis de redes sociales cuenta con una larga tradición en las Ciencias Sociales, sin embargo, las formulaciones teóricas sobre el capital social y sus implicancias para la formulación de políticas y los procesos de desarrollo en general han resultado en un renovado interés por parte de cientistas sociales, funcionarios, organismos y agencias preocupadas por la superación de situaciones de pobreza y exclusión social. La constitución de redes sociales a partir del accionar de organizaciones comunitarias es la temática de esta investigación.

El capital social consiste, brevemente, en un recurso que surge de las relaciones sociales, gracias a las cuales los actores se aseguran los beneficios en virtud de la pertenencia a redes $\mathrm{u}$ otras estructuras sociales. El capital social consiste en "rasgos de organizaciones sociales, como redes, normas y confianza, que facilitan la acción y la cooperación en beneficio mutuo" (Putnam, 1993: 35). Más recientemente se ha definido el capital social como "la simpatía de una persona o un grupo hacia otra persona o grupo que puede producir un beneficio potencial, una ventaja y un tratamiento preferencial para otra persona o grupo de personas más allá del esperado en una relación de intercambio" (Robison, Siles, Smith, 2003). De este modo, el capital social consiste en los sentimientos de solidaridad que una persona o grupo sienten por otra persona o grupo (Forni, Siles \& Barreiro, 2004).

La presente investigación procura hacer un aporte al estudio de los procesos actuales de organización comunitaria y el capital social que se genera, tomando variadas organizaciones sociales en contextos de exclusión, estudiando asimismo las redes que en ellas se forman. Los objetivos planteados en esta investigación consisten en analizar a través de qué estructuras y procesos de asociación u organización comunitarias se genera capital social en contextos de exclusión, para comprender si la construcción de capital social es fomentada por el establecimiento de vínculos estrechos ("cercanía de las redes sociales"), o si más bien surge de 
la capacidad de los actores para establecer diferentes relaciones fuera de su grupo de pertenencia ("las conexiones puente"). Es así que se propone:

- Describir las diferentes experiencias organizativas a partir de sus orígenes, objetivos, estructura de organización, miembros, etc.

- Indagar sobre el tipo de relaciones que establecen las organizaciones comunitarias entre sí y con otros tipos de organizaciones o actores sociales dentro y fuera de su comunidad.

- Determinar y analizar qué tipos de capital social se genera como resultado de estas experiencias organizativas (unión, vinculación, aproximación).

\section{Estrategia metodológica}

La estrategia metodológica para el desarrollo de este trabajo es cualitativa. La selección de los casos está guiada por la comparación de distintas redes de organizaciones comunitarias en el área metropolitana de Buenos Aires. Dado que nuestro principal objetivo es analizar a partir de qué procesos y estructuras organizativas es posible obtener resultados en términos de capital social, se presta atención tanto a la estructura interna de las organizaciones de base, como así también a la estructura de las relaciones que establecen las mismas en cada uno de los barrios seleccionados.

La unidad de análisis son las organizaciones comunitarias seleccionadas y las redes que desde éstas se desarrollan vinculando organizaciones, grupos, empresas y agencias gubernamentales. Las unidades de recolección son tanto los diferentes miembros de las organizaciones comunitarias como informantes claves y/o miembros de las comunidades. El criterio de selección de las diferentes organizaciones consiste en la diversificación de las formas de organización seleccionadas, a fin de poder establecer comparaciones significativas en torno a la generación de capital social. Sin embargo, cabe aclarar que las mismas no agotan las 
posibles configuraciones de redes a partir de organizaciones comunitarias. El trabajo de campo fue realizado durante los años 2005 y 2006. Las técnicas de recolección utilizadas son observación no participante (para captar los posibles entrevistados, y para comprender la dinámica de las organizaciones), entrevistas semi estructuradas y entrevistas en profundidad, las cuales permiten indagar sobre los orígenes de las organizaciones, su trayectoria, sus miembros y las redes establecidas.

\section{La articulación de redes sociales y los tipos de capital social}

Si bien la preocupación por las fuentes de la solidaridad social y los vínculos puede rastrearse hasta los propios orígenes de las Ciencias Sociales, en los últimos años el concepto de capital social ha generado un importante debate académico. Aquí presentamos brevemente algunas definiciones sistemáticas y contemporáneas de capital social, como aquellas que encontramos en autores tales como Coleman, Putnam, Burt y Granovetter.

Coleman define el capital social como "...una diversidad de entidades con dos elementos en común: todas consisten en algún aspecto de estructuras sociales y facilitan cierta acción de los actores (ya se trate de personas o actores corporativos) dentro de la estructura" (Coleman, 1990: 302). Es decir, se trata de un recurso de la estructura en la cual los individuos están insertos, que ayuda a lograr objetivos personales y que en caso de ausencia de este capital no podrían alcanzarse. Coleman enfatiza en el grado de cercanía (closure) de las relaciones entre los individuos que facilitará la acción colectiva, donde los beneficiarios del capital social serán todos aquellos que formen parte de esa estructura social.

Mientras Coleman enfatiza la densidad de las redes como condición para el surgimiento del capital social, otro autor, M. Granovetter, hacia 1974 expresaba una idea diferente a través del concepto de "fortaleza de los vínculos débiles" para referirse por ello a la capacidad de las influencias indirectas exteriores al círcu- 
lo inmediato de la familia y los amigos más cercanos para servir como un sistema informal de referencia de empleos. Él señala que “...aquellos con quienes estamos débilmente vinculados son más propensos a moverse en círculos distintos al propio y, por lo tanto, tendrán acceso a una información diferente a la que nosotros recibimos" (Granovetter, 1973). Burt va a nutrirse de esta fuente de inspiración para destacar casi veinte años más tarde una concepción semejante en la cual, según su opinión, es la relativa ausencia de vínculos (que da en llamar "huecos estructurales") aquello que facilita la movilidad individual. Esto es así en tanto que, como explica el autor, las redes densas tienden a transmitir información redundante, mientras que los vínculos más débiles pueden ser fuentes de nuevos conocimientos y recursos (Portes, 1999).

De la literatura presentada hasta aquí surge la centralidad de la conformación de redes sociales, aunque sin estar exenta de controversias a su interior. De acuerdo al argumento denominado "la cercanía de las redes sociales" perteneciente a J. Coleman, a medida que el grado de interdependencia entre los individuos aumenta (a raíz del establecimiento de relaciones de obligaciones y expectativas recíprocas) la densidad de las redes se incrementa generando altos niveles de cohesión intra-grupo, condición sine qua non para la creación de capital social. Esto es así porque sólo a partir de la existencia de relaciones lo suficientemente estrechas es posible el surgimiento de un sistema de normas y sanciones, el que influirá positivamente en el desarrollo y la continuidad de relaciones basadas en la confianza y reciprocidad.

Burt, en cambio, enfatiza el papel de "los agujeros estructurales" (structural holes) y "las conexiones puente". Desecha la importancia de la densidad de las redes y se enfoca en la calidad de las mismas, midiéndose ésta en función de la posibilidad de acceso a información referente a entornos lejanos e inaccesibles al individuo por sí solo. Burt concuerda con Coleman en que los individuos mejor conectados son quienes disfrutan de mayores 
beneficios. El desacuerdo aparece a la hora de definir qué significa estar "mejor conectado" (Burt, 2000). El autor, haciendo una observación sobre la estructura social de mercado, concluye que aquellos individuos cuyas relaciones logran superar los agujeros estructurales, son quienes cuentan con una ventaja competitiva respecto del resto; son quienes cuentan con un grado mayor de capital social, en tanto sus redes de relaciones le otorgan acceso a mayor información, la que le brinda posibilidades de acción más amplias. Puede señalarse entonces que para Burt, la construcción de capital social no parte del establecimiento de vínculos estrechos, sino de la capacidad de los actores para establecer diferentes relaciones fuera de su grupo de pertenencia (Forni, Siles \& Barreiro, 2004).

De lo referido hasta aquí puede decirse que el capital social es fundamentalmente relacional y sólo puede generarse a partir de vínculos o relaciones entre agentes (sean estos individuales o colectivos). La definición desde la que partimos para hablar de red social es la siguiente: "Se trata de un conjunto de actores (o puntos, nodos o agentes) entre los que existen vínculos (o relaciones). Las redes pueden tener muchos o pocos actores y una o más clases de relaciones entre pares de actores" (Hanneman, 2000, cap. 1: 3). Las redes también sirven para conectar a diferentes segmentos de la sociedad (Robison, Siles \& Schmid, 2003). Así como las relaciones que se establecen entre familiares, amigos o compañeros de trabajo generan frecuentemente vínculos informales que a su vez constituyen pequeñas inversiones en capital social, también nos encontramos con "formas más elevadas de participación social": las asociaciones comunitarias. Pero tanto una como otra forma son muy importantes en el sostenimiento de las redes sociales (Putnam, 2000).

El análisis de las relaciones inter-organizacionales requiere entonces de la aplicación de las formulaciones hechas por Granovetter acerca de la importancia de los vínculos débiles. Al analizar el capital social a nivel comunitario en zonas de exclusión so- 
cial, se parte de la base que la segmentación y el aislamiento son rasgos característicos de la pobreza. Si se concluye que el proceso de segmentación lleva implícita la homogeneidad social en los contactos de las personas pobres, sus consecuencias se traducen en pocas oportunidades de superar su situación actual. Es por ello que en el presente trabajo creemos que es importante tomar en cuenta los vínculos que las personas y las organizaciones de la comunidad establecen tanto dentro como fuera de ésta, para conocer los distintos tipos de capital social que se generan (Forni, Siles \& Barreiro, 2004), a saber:

- Niveles intensivos de capital social son aquellos que existen entre los miembros de una familia o amigos cercanos; son llamados bonding social capital o de unión. Se basan en el afecto y la preocupación por el otro. Existen en relaciones socialmente estrechas.

- Otro tipo de capital social que existe en relaciones medianamente estrechas es el denominado linking social capital o de vinculación. El mismo se basa en los sentimientos de compañerismo y buena voluntad recíproca que puede existir entre personas de la misma condición e iguales recursos.

- Niveles de menor intensidad de capital social son denominados bridging social capital o de aproximación. Este nivel se basa en los sentimientos de respeto o conciencia de la existencia del otro que puede haber entre personas que mantienen una relación asimétrica de poder e influencia. Existe en las relaciones asimétricas entre personas que tienen pocos puntos de coincidencia y diferencias importantes en cuanto a los recursos que poseen.

Asimismo, diferentes investigadores desconfían del concepto de capital social a raíz de las instituciones y los intereses sociopolíticos con que ha sido identificado: "su origen en la academia estadounidense; su divulgación a raíz de un trabajo de investigación (Putnam, 1993) que ha sido criticado tanto por su 
débil lectura de la historia italiana como por la subvaloración de cuestiones de economía política (Fox, 1996); y su popularidad tan notoria en el Banco Mundial" (Bebbington, 2005). Otros indican que el capital social no es realmente una forma de capital como el capital físico, el financiero, el humano, el cultural y el natural. Sin embargo reúne los requisitos que debe reunir el capital para serlo (ver Coleman, 1990: 304; Robison, Siles y Schmid, 2003: 60).

Antes de continuar, es necesario aclarar que si bien la literatura sobre el capital social subraya sus beneficios, debe agregarse a ello el debate sobre los efectos menos deseables o "negativos" de este término (Portes, 1999) tales como: exclusión de extraños, reclamos excesivos a los integrantes del grupo, restricciones a la libertad individual, normas niveladoras hacia abajo y la antipatía que siente una persona o grupo por otra persona o grupo (ver Robison, Siles y Schmid, 2003). Igualmente cabe aclarar que “Uno puede hablar de capital social negativo cuando se emprende una acción con el fin de perjudicar o explotar a otros, pero ésta es una complicación innecesaria si se define el capital social como las cosas (sociales, psicológicas o emocionales) que contribuyen a una acción colectiva mutuamente beneficiosa, o a la cooperación en términos más generales" (Uphoff, 2003: 120).

\section{Las organizaciones y sus redes}

Los casos considerados se diferencian entre sí, en cuanto a las características de las organizaciones, y por las especificidades propias de las redes de las que forman parte al interior y al exterior de las organizaciones de la sociedad civil (en adelante OSC). Varían en el tipo (género, militancia religiosa y/o política, etc.) y cantidad de individuos que las integran, así como por la población objetivo (hogares pobres, trabajadores desocupados, mujeres inmigrantes, la comunidad en general) y en la cantidad de beneficiarios.

A su vez, persiguen finalidades distintas (mejoramiento de la vivienda, formas de organización autogestionadas, financia- 
miento y asistencia a la comunidad boliviana, mejoramiento de las condiciones de trabajo de los recolectores de residuos) y consecuentemente llevan adelante diferentes actividades. Una similitud importante entre los casos analizados está relacionada con el contexto de su surgimiento. Todos emergen a partir de la preocupación por la resolución de problemáticas locales. Por lo tanto incluyen a diversas organizaciones comunitarias locales, mientras que asimismo se encuentran articuladas en redes más amplias, poniéndose en contacto con organizaciones e instituciones alejadas del círculo más próximo de la comunidad. La mayoría de las organizaciones comunitarias que integran esta investigación tienen como punto de partida la crisis socio-económica que se desató a fines de 2001. Los diversos proyectos se originan como producto de la emergencia y de las necesidades extremas imperantes en ese momento.

\section{Los grupos solidarios de microcrédito para el} mejoramiento de la vivienda (Fundación Pro Vivienda Social), Cuartel V, Moreno, Gran Buenos Aires

La Fundación Pro Vivienda Social (en adelante FPVS) fue creada en 1992 y tiene como objetivo contribuir a la solución del problema de la pobreza, concentrando su accionar en el mejoramiento de la vivienda y de las condiciones de vida de los sectores más necesitados, buscando impulsar su protagonismo en la solución de sus conflictos. Para lograrlo, actúa asociativamente con organizaciones comunitarias locales. La zona de acción de la Fundación es el noroeste del segundo cordón del Área Metropolitana de Buenos Aires. El foco principal de las operaciones de microcrédito llevadas a cabo por la organización es el partido de Moreno, donde se encuentra uno de los índices más elevados de hogares con necesidades básicas insatisfechas entre los 24 municipios del Gran Buenos Aires. Dentro del partido, la localidad de Cuartel V es aquella donde se concentra la población de menores recursos (fuente: www.moreno.gov.ar). La situación habitacional es muy problemática en esta zona. La Fundación colabora en la solución 
habitacional de Cuartel V, reduciendo los tiempos que implican mejorar una vivienda, gracias al otorgamiento de microcréditos. Específicamente se entiende por éstos a aquellos pequeños empréstitos otorgados a sectores sociales excluidos de poder acceder o calificar a préstamos bancarios (Cheston \& Reed, 1999).

La Fundación otorga créditos que se respaldan con una garantía solidaria. La misma permite a personas sin documentación de ingresos y vivienda, ser sujetos de crédito, facilitando las condiciones de acceso al financiamiento de esta comunidad y acompañando el proceso por el cual la familia va mejorando su vivienda. Al conformarse los grupos se contribuye a bajar el riesgo crediticio y por lo tanto la tasa de interés. Todos los miembros actúan como garantes co-responsables ante la devolución del crédito grupal, por lo tanto, si bien pueden existir ciertas diferencias en el monto que a cada uno de los integrantes del grupo se le otorga, desde la Fundación se trata que éste sea relativamente homogéneo, para que en caso de tener que recurrir a la garantía solidaria, la misma se pueda cumplir con mayor facilidad. Los integrantes se eligen entre sí sin intervención de la Fundación. Los grupos deben estar conformados por una cantidad de entre 3 y 5 personas, que difieren en el tipo de vínculos que existe entre ellos: son generalmente familiares, vecinales o mixtos. Asimismo, al menos uno de los integrantes debe ser, como condición, ex cliente de la Fundación.

FPVS está organizada del siguiente modo: por una parte se encuentra la Sede Central, encargada de establecer los lineamientos estratégicos de acuerdo a los avances del Programa, así como también se ocupa de la gestión de financiamiento. Por otra parte hallamos la Subsede, localizada en el mismo barrio donde la Fundación actúa con los grupos solidarios. Por otro lado encontramos un vínculo entre la Fundación y la Mutual El Colmenar, dada la trayectoria que tienen trabajando juntas no sólo desde los primeros acercamientos de la Fundación en el barrio, momento en que fue apoyada por la Mutual, sino que también las liga 
un vínculo de colaboración y asesoramiento en la actualidad. El vínculo entre miembros de FPVS y El Colmenar se remonta a los orígenes de esta última a fines de la década del ochenta. Se trata de una mutual dedicada primariamente a brindar transporte público (colectivos) a los habitantes de todos los barrios de Cuartel V. También llevan adelante acciones en los campos de educación, salud, provisión de alimentos, deportes, etc. (Forni, 2002).

\section{Movimiento de Trabajadores Desocupados (MTD) \\ Centro para la Educación y Formación de Cultura Comunitaria (CEFOCC), Barrio La Juanita, La Matanza, Provincia de Buenos Aires}

A mediados de los años 90s, se producen movilizaciones y cortes de ruta en localidades de las provincias de Neuquén y Salta, como reacción al cierre de sendas plantas refinadoras de petróleo, fuente de las economías locales por más de cinco décadas. El modo de acción de estas primeras "puebladas" se caracteriza por el corte de las rutas, con el propósito no sólo de paralizar las vías de acceso, sino también de dar visibilidad al reclamo. Con el crecimiento del desempleo y la exclusión social, estos primeros levantamientos se multiplican a todo lo largo del territorio nacional, poniendo en evidencia una crisis socioeconómica generalizada, cuya profundización desatará los acontecimientos de finales de 2001 en Buenos Aires, Argentina. "Piqueteros" es un movimiento relativamente plural en lo político y heterogéneo en su composición. (Svampa y Pereyra, 2003)

El Movimiento de Trabajadores Desocupados (MTD) de La Matanza, ha tenido un papel relevante en la historia de las agrupaciones piqueteras. Su líder, Héctor "Toti" Flores, convocó la primera "marcha contra el hambre, la represión y la desocupación", en septiembre de 1996 y fue también el encargado de organizar la primera Asamblea Nacional del movimiento hacia fines de 1997. En años recientes numerosas organizaciones de piqueteros se han vinculado al gobierno nacional a traves del nombramiento 
de algunos de sus principales dirigentes como funcionarios y la recepción de programas sociales oficiales. Desde sus orígenes, el MTD - La Juanita ha asumido una clara oposición al asistencialismo de las políticas públicas, que se plasma en el rechazo de planes sociales y de ayuda alimentaria.

Si bien en cierta medida, todas las agrupaciones piqueteras tuvieron en sus orígenes un fuerte anclaje local, aquello que resulta más innovador y distingue al MTD - La Juanita es, justamente, la decisión explícita de concentrar su accionar en "el barrio". Así, a comienzos de 2001 nació el proyecto CEFOCC (Centro para la Educación y Formación de Cultura Comunitaria), cuyo principal objetivo es generar una cultura del trabajo alternativa. Según el relato de sus miembros, tomando como referencia a otros movimientos sociales populares en auge hacia fines de los noventa (Zapatistas, Sin Tierra, etc.), optaron por el camino de la autogestión, independizándose de los planes asistenciales oficiales. Han dejado de lado el carácter originalmente reivindicativo de piqueteros para adoptar una actitud negociadora de intercambio. Esta postura los ha condenado al aislamiento respecto de un gran número de agrupaciones piqueteras, al tiempo que les ha proporcionado una importante exposición mediática. Es frecuente la aparición del CEFOCC en los medios gráficos, como parangón de actividad comunitaria autogestionada y de creación de vínculos alternativos que exceden la relación con el estado.

Si bien el proyecto CEFOCC se conforma a principios de 2001, su estructura se afirma entre 2003 y 2004. La primer actividad de la agrupación piquetera tendiente a la generación de trabajo es la iniciativa editorial. A mediados de 2001, la agrupación decide editar y distribuir un libro acerca de su experiencia en el primer Foro Social Mundial (2001). Los fondos recaudados con esta primera edición se destinarán a la apertura del que constituye el núcleo del proyecto y - al día de hoy - uno de los nodos más importantes del CEFOCC, el Jardín de Infantes. Este proyecto data de principios de 2002 y constituye, según "Toti" Flores, el 
de mayor "anclaje social". El Jardín, que recibe a unos 55 chicos diariamente, impone como único requisito la participación de los padres en reuniones semanales de la "comunidad educativa" en las cuales se buscan, a través del consenso, pautas entre la escuela y el hogar.

El otro nodo alrededor del cual gira el accionar comunitario del CEFOCC, es el taller de costura. En él se capacita a gente del barrio y se trabaja por turnos de 8 horas diarias, seis días a la semana. El emprendimiento involucra a unas 10 personas. La actividad del taller ha generado el establecimiento de relaciones con instituciones internacionales, así como con empresarios. Además de estos dos proyectos principales, el CEFOCC cuenta con una panadería artesanal (aproximadamente cuatro personas) relevante para las estrategias alimentarias de los hogares del barrio y un albergue para estudiantes e investigadores en ciencias sociales extranjeros, con una capacidad para 2-4 personas que le ha brindado visibilidad internacional así como ingresos monetarios.

\section{Cooperativa "El Ceibo", Palermo, Ciudad de Buenos Aires}

"El Ceibo Trabajo Barrial" es una cooperativa de vivienda fundada en 1989 por un grupo de familias residentes en casas tomadas en las zonas de Palermo y Villa Crespo de la Ciudad de Buenos Aires. Desde su conformación ésta venía trabajando no sólo en temas de vivienda, sino también en otras problemáticas que afectaban a las familias de la zona, tales como salud, violencia familiar, procreación responsable y escolaridad, entre otras, siempre tratando de responder de forma integral a las necesidades de las familias. Muchos de los miembros de la cooperativa vivían del cirujeo, actividad considerada ilegal por esos años. El término "cirujeo" se refiere a la actividad de separar materiales reciclables de la basura para su futura venta. Los miembros del Ceibo se identifican como "cirujas", y no como "cartoneros", un 
término que se ha difundido de forma masiva después de la crisis de 2001, cuando mucha más gente empezó a dedicarse a esa actividad. Lo prefieren porque no solamente separan cartón, sino muchos otros materiales también, y porque "ciruja", para ellos, implica una persona que venía desarrollando esa actividad desde antes de la crisis.

En el 2001, a partir de un impulso dado por el Instituto Movilizador de Fondos Cooperativos (IMFC), se conforma la "Cooperativa de Recuperadores Urbanos El Ceibo" (El Ceibo RSU), constituida como una entidad de provisión y servicios para recolectores de materiales reciclables. A la cooperativa pertenecen 100 familias. Aquí se presta atención principalmente al proyecto socio-ambiental llevado a cabo por El Ceibo RSU. Dos pasos importantes en la conceptualización y formación de este proyecto socio-ambiental fueron, primero, su postulación a la competencia "Development Marketplace", organizada por el Banco Mundial en enero de 2002, y segundo, la firma de un convenio en agosto de 2002 entre el Gobierno de la Ciudad de Buenos Aires y la cooperativa "El Ceibo". La zona de implementación del proyecto comprende el perímetro de Avda. Córdoba, Godoy Cruz, Avda. Santa Fe y Julián Alvarez. Los pasos en la implementación del proyecto fueron:

a) Trabajo previo de promoción ambiental en domicilios, locales comerciales y edificios de la zona, realizado por el equipo de "promotores ambientales". La tarea de los promotores consiste en brindar información sobre residuos recuperables a los vecinos para incentivar el cambio de hábitos en cuanto a la selección y separación de estos elementos.

b) Se integran al trabajo los recuperadores, quienes proceden a retirar puerta a puerta los materiales recuperables (previamente separados por los vecinos), y los transportan hasta el centro de acopio de la cooperativa. 
c) En el centro de acopio se realiza la separación de los materiales recuperables y su almacenamiento para su posterior venta.

4. Los feriantes bolivianos de La Salada y el microcrédito (FIE-Gran Poder), Lomas de Zamora, Provincia de Buenos Aires

El Fondo de Incentivos Económicos (FIE) Gran Poder S.A. opera en la Argentina desde mediados de 2001, con el propósito de ofrecer servicios financieros a clientela de bajos ingresos y asistir a la comunidad de inmigrantes bolivianos. Es una filial de la Institución Micro Financiera IMF FIE S.A. de Bolivia que se destaca por su gran expansión y más de 20.000 clientes en ese país. Operan bajo la misma razón social el Fondo Financiero Privado de Bolivia y la ONG FIE, siendo ésta la principal accionista de FIE en la Argentina. La primera sucursal que se abre al público se encuentra en el barrio de Liniers, área donde existen gran cantidad de comercios, restaurantes y servicios que pertenecen a inmigrantes y abastecen a la comunidad boliviana en Buenos Aires. En la actualidad cuentan con cuatro agencias en total (son 50 la cantidad de individuos que integran las agencias y cada una de ellas cuenta con aproximadamente 1500 clientes); las tres que se sumaron a la primera se encuentran en La Ferrere, Balvanera, y Lomas de Zamora. FIE es una de las IMFs más importantes de la Argentina con una cartera bruta de préstamos a noviembre de 2005 de más de 4 millones de dólares (Maradeo, 2005) y casi 2000 clientes activos.

Los servicios financieros que prestan son básicamente dos: créditos y envío de remesas al exterior. Para el primero de los productos, ofrecen varias líneas de crédito para microemprendedores. Las actividades que financian son producción de textiles, alimentos y algunos servicios). Esta línea de micro créditos es por un monto de 2000 a 3000 pesos argentinos, también otorgan préstamos hipotecarios, destinados a compra de vivienda. En el caso 
de las remesas, es una actividad que retoman recientemente, ya que se habían suspendido los envíos luego de la crisis del 2001. Los créditos que otorgan son individuales y la garantía de los mismos es la propia persona. Mediante visitas del evaluador y entrevistas, se determina la capacidad de repago del prestatario. El papel del evaluador es de promoción, evaluación, mantenimiento y recuperación de los créditos. En esta evaluación se incluyen cuestiones objetivas, ya que se realizan entrevistas a vecinos y referentes, se analiza cómo el emprendedor trabaja, y se diseña un crédito a medida, ya que la modalidad de repago se acuerda con el prestatario. Debe subrayarse el hecho de que FIE prestaba a miembros de la colectividad boliviana (nativos o descendientes), en tanto se pensaba que el boliviano tenía mejores condiciones de pago, y sólo muy recientemente empieza a incluir argentinos en su operatoria.

\section{Capital social: ¿existente o ex post?}

La búsqueda de respuestas a las necesidades ha impulsado el surgimiento de una amplia variedad de experiencias de articulación entre organizaciones. En el transcurso del trabajo de campo pudo observarse que las redes que la propia gente tiene de vecindad, de familiaridad o de relación de trabajo están conformadas y son previas y su existencia se presenta como condición necesaria para el desarrollo de vínculos más debiles con organizaciones más distantes.

En el caso de Fundación Pro Vivienda Social, ésta debió aliarse con la mutual "El Colmenar", dada su necesidad de legitimación en el área para que fuera posible la instalación de una línea de crédito para el mejoramiento de la vivienda. El lanzamiento del Programa se hizo en asociación con la mutual, fortaleciendo y legitimando a la Fundación en la zona, como un paso necesario para su supervivencia y éxito en la prosecución de sus objetivos. (Forni, 2002). Es decir que se comenzó a trabajar a partir del capital social de "El Colmenar" y su vinculación con los habitantes 
de la zona. Además, a partir del análisis del proceso de conformación de los grupos solidarios, encontramos que éstos se forman en parte gracias al conocimiento y relación previa entre los integrantes. En algunos casos eligen familiares, en otros, vecinos o compañeros de trabajo, pero el elemento en común es que todos fueron recomendados por algún integrante del grupo.

Una situación similar ocurre con el caso de FIE Gran Poder S.A., pues cuando esta organización comienza a trabajar en Argentina, ya existía una red de vínculos que implicaban solidaridad y confianza mutua entre los inmigrantes, estrechamente vinculados por su nacionalidad, costumbres, tradiciones, actividades productivas y una situación económica común. Inferimos por un lado la existencia de capital social de vinculación, a partir de esa experiencia común, que pone de manifiesto sentimientos de compañerismo y buena voluntad recíproca para hacer frente a la sensación de desarraigo y exclusión. También cabe destacar la presencia de capital social de unión, ya que son muy comunes los casos de familias cuyos miembros se van instalando paulatinamente en Argentina.

Una primera conclusión de esta investigación es que es necesaria la existencia previa de capital social entre los integrantes de la comunidad, para que las estrategias de articulación con otros actores más distantes sean viables. Por lo tanto, creemos que el capital social en el desarrollo de las mismas es fomentado por las OSC, pero la existencia de capital social es previa a la aplicación de los diversos programas.

\section{La maximización del capital social}

En este trabajo de investigación encontramos que las redes horizontales densas sostienen la cooperación al interior de la comunidad, pero las redes que logran atravesar los agujeros estructurales alimentan una cooperación más amplia. Los excluidos, al disponer de escasos recursos financieros, cuentan con su capaci- 
¿Cómo generar capital social en contextos de exclusión?:Experiencias de organizaciones comunitarias y sus redes sociales - Pablo Forni y Mariana Nardone

dad de generar capital social con personas muy diferentes a ellos mismos mediante "vínculos débiles".

Siguiendo la tipología de capital social, podría decirse que entre los grupos solidarios y la Fundación Pro Vivienda Social existe capital social de puente, fomentado a través de contactos más o menos formales. Dejamos planteado como hipótesis que así como los clientes utilizan los vínculos más formales y distantes en la red para la obtención de nuevos recursos, por su parte la Fundación convierte el capital social existente entre los vecinos de Cuartel V en garantía solidaria.

En el caso de los feriantes bolivianos, éstos pueden mejorar su situación al gestionar socialmente los recursos y las necesidades, es decir, gracias a su alianza, sustentando su unidad en el capital social que generan. Puede decirse que la relación entre los microemprendedores y FIE Gran Poder S.A. por lo general consiste en una vinculación de transferencia de fondos, de poca cercanía y basada en vínculos débiles. Se pudo así captar la capacidad de las influencias indirectas exteriores al círculo inmediato propio -de la familia y los vecinos-, que sirven como un sistema de acceso a recursos diferentes. Podría decirse que FIE utiliza como recurso estratégico el capital social -tanto de unión como de vinculación- que caracteriza a la comunidad boliviana en la Argentina y que además dicho accionar genera conexiones puente que se traducen en beneficios para sus clientes.

Pero a su vez, las propias OSC maximizan el capital social de puente, generando lazos lo más distantes posibles. En el caso de CEFFOC, uno de sus proyectos más reconocidos, el taller de costura, se ha equipado por medio de donaciones que constan de seis máquinas de coser cedidas por la Embajada de Japón y el programa de TV "Ser Urbano" y una máquina estampadora donada por el diseñador Martín Churba. En el taller se capacita a gente del barrio; el emprendimiento involucra a unas 10 personas. La actividad del taller ha generado una serie de contactos con instituciones nacionales e internacionales, así como con ins- 
tituciones y empresas distantes geográfica y socialmente. Hacia el año 2003 Flores y la Fundación Poder Ciudadano, una ONG de fuerte peso político en Argentina, se pusieron en contacto, en tanto que mientras el primero buscaba capacitación, la segunda quería demostrar que se podía trabajar el tema de la construcción de ciudadanía con organizaciones de base. A través de Poder Ciudadano, Flores y sus compañeros se vincularon a principios de 2004 con el diseñador Martín Churba, quien encargó la fabricación de unos guardapolvos de vanguardia que se presentaron en el desfile Buenos Aires Fashion 2004. Los guardapolvos llevaban la marca de Churba "Tramando" y el eslogan del taller del CEFOCC "Pongamos el trabajo de moda". Este hecho suscitó la atención de la prensa y de la Agencia de Cooperación Internacional de Japón (JICA); tras algunas negociaciones, se comenzó con una exportación de pequeña escala a Japón.

De la misma manera, La Cooperativa El Ceibo ha podido ampliar su accionar en tanto que a lo largo de los años, ha desarrollado relaciones con instituciones de todo tipo: empresas privadas de recolección de basura (Cliba), organismos públicos (Gobierno de la Ciudad de Buenos Aires), representaciones de gobiernos extranjeros (Embajadas de los Estados Unidos y Canadá), fundaciones (Inter-American Foundation), organizaciones no gubernamentales (Greenpeace, Conciencia, IMFC, COSPE), y organismos multilaterales (Banco Mundial, OEA, Naciones Unidas), entre otras.

Retomando aquí -al respecto de las relaciones inter-organizacionales- las formulaciones de Granovetter acerca de la importancia de los vínculos débiles, encontramos que los casos analizados logran disminuir la segmentación y el aislamiento propios de la exclusión social. El alcance de tales logros se debe en parte al establecimiento de redes densas al interior de la población, aunque asimismo ésta se vale de vínculos más débiles que pueden generar nuevos recursos y beneficios, generando mayores oportunidades de superar su situación. 


\section{El rol del capital social en la consolidación del tercer sector}

La articulación en redes por parte de las OSC es un proceso importante en lo que respecta a las relaciones con el ámbito gubernamental. Aquellas se originan ante un Estado incapaz de ser el único vector del desarrollo, y frente a instituciones ausentes o sin respuestas a diversas problemáticas dentro de la esfera social. En la actualidad nos encontramos frente a una amplia trama de OSC, destinadas a colaborar en la satisfacción de las demandas que surgen de los sectores más necesitados de la sociedad. Tal es así que el Programa de las Naciones Unidas para el Desarrollo (PNUD) ha asignado al trabajo de esas organizaciones como la fuente del capital social: “...es decir, elementos de organización social, verdaderas redes sociales alrededor de valores compartidos como solidaridad, respeto, participación, responsabilidad y confianza, que facilitan la coordinación y la cooperación en beneficio mutuo" (PNUD/BID, 1998: 11).

El tercer sector, entendido brevemente como el conjunto de organizaciones de la sociedad civil orientadas hacia el bien común (Filmus, Arroyo y Estébanez, 1997), va emergiendo, abriéndose paso entre el Estado y el mercado, confluyendo en nuevas relaciones entre ellos (de allí su categoría residual de "tercer sector" por ser organizaciones que no son ni gubernamentales ni comerciales). Surgen de esta manera nuevas formas de acción colectiva en la esfera de lo social que se desarrollan por fuera del ámbito político, timoneadas por Organizaciones No Gubernamentales (ONGs) con grupos de trabajo conformados por profesionales, técnicos y voluntarios (Filmus, Arroyo y Estébanez, 1997). Según la definición del Banco Mundial, las ONGs están consideradas como "...cualquier organización voluntaria de la sociedad civil, excluyendo los grupos económicos. Sugiere el uso del término 'organización no gubernamental' para aquellas organizaciones que llevan a cabo acciones para promover el desarrollo comunitario, proveer servicios sociales básicos, proteger el 
medio ambiente y promover los intereses de los pobres" (Filmus, Arroyo y Estébanez, 1997: 25).

A manera de ilustración, el Movimiento de Trabajadores Desocupados (MTD) de La Matanza, ha tenido un papel relevante en la historia de las agrupaciones piqueteras. Prácticamente desde sus orígenes, el MTD - La Juanita ha asumido una clara oposición al asistencialismo de las políticas públicas, que se plasma en el rechazo de planes sociales y de ayuda alimentaria. Han dejado de lado el carácter originalmente reivindicativo de las organizaciones de piqueteros para adoptar una actitud negociadora de intercambio, no ya con las distintas instancias gubernamentales, sino con otros actores del tercer sector, instituciones internacionales y sector privado. En suma, el hecho de integrarse y extender lazos con otro tipo de organizaciones le brinda importantes oportunidades para obtener recursos y ampliar las actividades, al mismo tiempo que modifica en forma sustantiva la estructura y funcionamiento internos de esta organización.

Como contra cara, es ilustrativo el caso de El Ceibo; en tanto que un paso importante en la conceptualización y formación del proyecto socio-ambiental llevado a cabo por El Ceibo RSU fue la firma de un convenio en agosto de 2002 entre el Gobierno de la Ciudad de Buenos Aires, representado por el ex Jefe de Gobierno, Dr. Aníbal Ibarra, y la Cooperativa "El Ceibo", representada por su Presidenta, Cristina Lescano. Los principales objetivos del convenio fueron: 1. Favorecer la promoción socio-ambiental en la ciudad; 2. Mejorar las condiciones de trabajo de los recolectores de residuos; 3. Facilitar el acceso al mercado laboral a personas de bajos recursos; e 4. Impulsar la concientización del vecino respecto del cuidado del medio ambiente y la creación de fuentes de empleo (Reynalds, 2002).

Es decir que se ha ido dando un cambio en años recientes en relación con la actitud de las administraciones locales. Los municipios de modo ciertamente heterogéneo y gradual prestan 
¿Cómo generar capital social en contextos de exclusión?:Experiencias de organizaciones comunitarias y sus redes sociales - Pablo Forni y Mariana Nardone

mayor atención a las organizaciones de base no dependientes de maquinarias políticas y reconocen (y al menos en el discurso apoyan) la existencia de redes interorganizacionales que las articulen. Este importante cambio se relaciona a dos factores: Primero, el desarrollo creciente del campo organizacional de las organizaciones de base o comunitarias que han ido volviéndose más visibles, brindando más servicios a sus beneficiarios y obteniendo reconocimiento y legitimidad a nivel societal. En segundo lugar, a los requerimientos de participación de organizaciones de la sociedad civil así como de instancias de articulación de las mismas por parte de programas sociales, sobre todo de aquellos cuya financiación está atada a organismos internacionales.

\section{Referencias bibliográficas}

Bebbington, A. (2005). “Estrategias de vida y estrategias de intervención: el capital social y los programas de superación de la pobreza”, en Arriagada, I. (editora), Aprender de la experiencia. El capital social en la superación de la pobreza, CEPAL, Santiago de Chile.

Burt, R. (2000). The Network Structure of Social Capital. University of Chicago and Europeen d'Administration d'Affairs (INSEAD).

(2000). Structural Holes versus Network Closure as Social Capital, University of Chicago and Europeen d'Administration d'Affairs (INSEAD).

Coleman, J. (1990). Foundations of Social Theory, Cambridge Mass.: Harvard University Press.

Cheston, S. y Reed, L. (1999). “Medición de la transformación: Evaluación y mejora del impacto del microcrédito". Ponencia presentada en la Reunión de Consejos de la Cumbre de Microcrédito Adbuja, Costa de Marfil, en: www.microcreditsummit.org/pdfs/ impactpapersp.pdf

Filmus, D. (coordinador), Arroyo, D. y Estébanez, M. E. (1997). El perfil de las ONGs en la Argentina, Banco Mundial-FLACSO, Argentina.

Flores, H. "Toti" (compilador) (2003). De la culpa a la autogestión, Ediciones Continente, Buenos Aires.

Forni, P. (2002). “La búsqueda de nuevas formas de organización popular: Del Consejo de la Comunidad a la Mutual 'El Colmenar'”, en: Forni, F. (comp.), De la exclusión a la organización. Hacia la exclu- 
sión de los pobres en los nuevos barrios del conurbano bonaerense, Ediciones Ciccus, Buenos Aires.

Forni, P., Siles, M. \& Barreiro, L. (2004). “¿Qué es el Capital Social y cómo Analizarlo en contextos de Exclusión?", en: www.jsri.msu.edu

Granovetter, M. (1973). "The Strength of Weak Ties", en American Journal of Sociology; vol. 78, n 6 (pp. 1360-1380).

Hanneman, R. A. (2000). Introducción a los métodos de análisis de redes sociales, Departamento de Sociología de la Universidad de California Riverside, en: http://revistaredes.rediris.es/webredes/textos/Introduc.pdf

Maradeo, J. (2005). "Microfinanzas en Argentina: Dificultades y Desafíos" Argentina, 6 de diciembre de 2005, en: http:/ / argentina.planetfinance.org/presentaciones/Juan_M_Maradeo.pdf

PNUD/BID (1998). El capital social: Hacia la construcción del índice de desarrollo Sociedad Civil de Argentina, Edilab Editora.

Portes, Alejandro (1999). "Capital Social: Sus orígenes y aplicaciones en la sociología moderna" en: Carpio, J. \& Novacovsky, I. (compiladores), De Igual a Igual. El desafío del Estado ante los nuevos problemas sociales, Fondo de Cultura Económica, Buenos Aires.

Putnam, R. (1993). "The prosperous community: social capital and public life", en Am. Prospect 13.

(1993). Making Democracy Work, Princenton University Press, New Jersey.

(2000). Bowling Alone: The Collapse and the Revival of American Community, Simon and Schuster, New York.

Reynalds, C. (2002). "De cartoneros a recuperadores urbanos", González Bombal, I. (ed.), Respuestas de la sociedad civil a la emergencia social, CEDES, Buenos Aires.

Robison, L., Siles, M. \& Schmid, A., (2003). “El capital social y la reducción de la pobreza: hacia un paradigma maduro" en Atria, R. y Siles, M. (compiladores), Capital social y reducción de la pobreza en América Latina y el Caribe: En busca de un nuevo paradigma, CEPAL - M.S.U., Santiago de Chile.

Svampa, Maristella y Pereyra, Sebastián (2003). Entre la ruta y el barrio, La experiencia de las organizaciones piqueteras, Editorial Biblos, Buenos Aires.

Uphoff, N. (2003). "El capital social y su capacidad de reducción de la pobreza", en: Atria, R. y Siles, M. (compiladores), Capital social y 
¿Cómo generar capital social en contextos de exclusión?:Experiencias de organizaciones comunitarias y sus redes sociales - Pablo Forni y Mariana Nardone

reducción de la pobreza en América Latina y el Caribe: En busca de un nuevo paradigma, CEPAL - M.S.U., Santiago de Chile, en: http:/ / www.eclac.cl/cgibin/getProd.asp?xml=/prensa/noticias/comunicados3/7903/P7903.xml\&xsl=/prensa/tpl/p6f. xsl\#top

Colaboraron en esta investigación: Lucrecia Barreiro; Inés Dahn; Gisela Davico; Gabriela García; Katherine Hutter; Sandra Lancestremere; María Eva Muzzin; Carla Pagura; María Laura Russo de Luchi y Marianela Sansone. 